Anal ysi s of cement pastes and nortars by a conbi nat i on of backscat ter-based SEM i nage anal ysi s and cal cul at i ons based on the Powers model

\begin{tabular}{|l|l|}
\hline 著者 & I gar ashi Shi $\mathrm{n}$ - i chi , Kawamur a M, hat anabe A. \\
\hline $\begin{array}{l}\text { j our nal or } \\
\text { publ i cat i on t i t l e }\end{array}$ & Cement and Concr et e Composi t es \\
\hline vol une & 26 \\
\hline nunber & 8 \\
\hline page r ange & $977-985$ \\
\hline year & 2004 11- 01 \\
\hline URL & ht t p: //hdl . handl e. net /2297/1826 \\
\hline
\end{tabular}




\title{
Analysis of cement pastes and mortars by a combination of backscatter-based SEM image analysis and calculations based on the Powers model
}

\author{
S. Igarashia ${ }^{*}$, M. Kawamura ${ }^{\mathrm{a}}$ and A. Watanabe ${ }^{\mathrm{a}}$ \\ ${ }^{\text {a }}$ Department of Civil Engineering, Kanazawa University, 2-40-20 Kodatsuno, Kanazawa 920-8667, \\ Japan
}

\begin{abstract}
Formation of microstructure in cement pastes and mortars were quantitatively analyzed by the SEM-BSE image analysis. Effects of water/cement ratio and of the addition of mineral admixtures on the contents of unhydrated cement particles and pores were discussed. The proportions of each phase obtained by the analyses were compared with proportions calculated on the Powers model. It was found from comparisons that the volume fractions of the residual cement and pores obtained by the image analysis did not contradict those estimated from the Powers model. Lower water/cement ratio pastes and those undergoing pozzolanic reaction showed less fine capillary pores. It was also found that large capillary pores still remained in the mixtures at long ages. The gel/space ratio in the Powers and Brownyard equation was calculated from the phase constituents determined by the image analysis. For mortars without mineral admixture, the gel/space ratio by the image analysis could be related to the strength.
\end{abstract}

Keywords: Backscattered electron image analysis, Degree of hydration, The Powers model, Capillary porosity

*Corresponding author. Fax:+81-76-234-4632

E-mail address: igarashi@t.kanazawa-u.ac.jp 


\section{INTRODUCTION}

The total porosity, pore size distributions, and specific surface areas have been used to characterize the pore structures in porous materials. In addition to these parameters, pore connectivity and tortuosity may be also important in the durability of concrete. Pore diameters in concretes range from $\mathrm{nm}$ to a few $\mathrm{mm}$. The mercury intrusion porosimetry (MIP) method has been commonly used to evaluate pore size distributions in cement-based materials. However, it should be noted that the pore structure revealed by the MIP method is not representative of the real structure in concrete because of the inappropriate assumption to be made for the complex network of pores [1].

Another method to evaluate the porosity and characteristics of coarse capillary pore structures is the quantitative SEM-BSE image analysis [2,3]. Pores as one of constituent phases in an original BSE image can be quantitatively evaluated by the procedures of image analysis. Based on the simple stereological principles, area fractions obtained for a $2 \mathrm{D}$ cross section are equal to volume fractions for the $3 \mathrm{D}$ real structure when materials have a completely random and isotropic nature[4]. The microstructure of cement paste can be considered to satisfy those stereological conditions. Thus, the imaging technique for BSE images is a method for quantitatively evaluating the actual 3D microstructure by analyzing information on 2D cross sections.

The pioneering works using imaging technique for revealing local variations of microstructure, e.g. porosity gradients in concretes were made by Scrivener and Pratt [5,6]. At early stages in the development of this technique, the area fraction of measurable image parameters was a key quantity to understand features of microstructure in concrete. Recently, the imaging technique for concrete has been extended to extract not only the total quantity, but also geometric features of phases of interest [7,8]. In view of recent advanced technology of diagnostic imaging system in the medical engineering, geography etc., it is expected to establish such a system in concrete science and engineering.

Four phases in cement paste, i.e. unhydrated cement particles, calcium hydroxide crystals, CSH and capillary pores, can be resolved by the imaging technique. Usually, only the total amount of each specific phase has been focused on. However, a few studies on the evolution of microstructure with an emphasis on 
quantitative interrelations between phases by image information are found. If the quantitative balance between phases is properly related to a reliable model for the hydration of cement, the image-based operations on the hydration of cement can give quantitative and/or qualitative information on the evolution of microstructure including features on a scale finer than the resolution of BSE images.

The object of this study is to quantitatively pursue changes in the amount of constituent phases with time in cement pastes and mortars by BSE image analysis. Pores and unhydrated cement grains, two phases that contrast in gray level, are examined to quantify their volume changes with time during the hydration of cement. It was assumed that variations in area fractions of these two phases can be directly related to each other by means of the degree of hydration of cement as determined by the image analysis. In the analysis, the results of image-based operations for apparent variations of the two phases are compared to predictions from the Powers model [9] to estimate the presence of fine pores less than the resolution. The effects of water/binder ratio and of the addition of mineral admixtures, on the microstructure of cement pastes and mortars were discussed in terms of the combination of image analysis and the Powers model. The validity of the dependence of the compressive strength on the gel/space ratio obtained by the BSE image analysis was also discussed.

\section{EXPERIMENTAL}

\subsection{Materials and Mix Proportion of Cement Pastes and Mortars}

The cement used was an ordinary Portland cement produced in Japan. A silica fume and a fly ash with a specific surface area of $20 \mathrm{~m}^{2} / \mathrm{g}$ and $0.345 \mathrm{~m}^{2} / \mathrm{g}$ were used as mineral admixtures (Table 1). The replacement levels of silica fume and fly ash were $10 \%$ and $15 \%$, respectively. The fine aggregate used in the mortars was a natural river sand with F.M. of 2.59. A polycarboxylic acid type superplasticizer was used in cement pastes with silica fume. Water/binder ratios used were $0.25,0.40$ and 0.60 . Mix proportions of the cement pastes and mortars are given in Table 2. 


\subsection{BSE image analysis}

Cylinders of $100 \mathrm{~mm}$ in length and $50 \mathrm{~mm}$ in diameter were produced. They were demolded at 24 hours after casting, and then cured in water at $20^{\circ} \mathrm{C}$. At the prescribed ages, slices about $10 \mathrm{~mm}$ in thickness were cut from cylinders for the BSE image analysis. They were dried by ethanol replacement and in the vacuum drying, and then impregnated with a low viscosity epoxy resin. After the resin hardened at room temperature, the slices were finely polished with $\mathrm{SiC}$ papers. The polished surfaces were meticulously finished with diamond slurry for a short time.

Samples were examined using an SEM equipped with a quadrupole backscatter detector. The BSE images were acquired at a magnification of $500 \times$. In order to avoid influences of interfacial transition zones around fine aggregate particles on results, regions of interest for acquiring images in mortars were taken sufficiently away from surfaces of sand particles. Taking account of statistical variations in the results of image analysis, ten fields in each specimen were randomly chosen and analyzed [6,10]. Each BSE image (e.g. Fig.1) consists of $1148 \times 1000$ pixels. The size of one pixel is about $0.22 \times 0.22 \mu \mathrm{m}$. A dynamic thresholding method was used to make binary segmentation based on the gray level histogram. In this method, information on contrast of neighbour pixels is also used for thresholding in each pixel. Pixels for unhydrated cement particles and for pores were tallied so as to obtain area fractions of the two phases. The stereology principles state that area fractions in $2 \mathrm{D}$ cross sections are equal to $3 \mathrm{D}$ volume fractions. It was assumed that volume fractions of hydration products (i.e. CSH and calcium hydroxide crystals) could be obtained by subtracting the volume of unhydrated cement particles and capillary pores from the volume of a sample.

The degree of hydration of cement $(\alpha)$ was calculated by Equation (1) $[6,11]$.

$\alpha=1-\frac{U H_{i}}{U H_{0}}$

where

$\mathrm{UH}_{\mathrm{i}}$ : area fraction of unhydrated cement particles at the age of $t_{\mathrm{i}}$

$\mathrm{UH}_{0}$ : initial area fraction of unhydrated cement particles (i.e. $\mathrm{t}_{\mathrm{i}}=0$ ) 
It was confirmed in advance that the volume fraction of cement in a mixture of cement and epoxy resin was closely equal to the volume fraction determined by the image analysis.

Representative BSE micrographs of admixture-free and fly ash-containing cement pastes are given in Fig.1. As found in Fig.1(b), brightness of fly ash particles were sufficiently different from that of unhydrated cement particles. Therefore, in the calculation of the degree of hydration of cement, it was easy to determine the threshold value in the gray level between unhydrated cement and fly ash particles. Silica fume particles cannot be resolved in the SEM-BSE examination. However, the degree of hydration of cement in silica fume and fly ash-containing cement pastes was able to be calculated based on the same procedure as for the pastes without admixture.

\subsection{Compressive strength tests}

Cylinder specimens of $50 \mathrm{~mm}$ in diameter and $100 \mathrm{~mm}$ in height were prepared according to JIS R 5201 and JSCE-F506. The specimens were cured under the same condition as those used in the SEM examinations. Compressive strength tests were conducted at the age of 1,3,7,28 and 91days.

\section{RESULTS}

\subsection{Constituent phase fractions and the degree of hydration in cement pastes}

Fig. 2 shows the volume fractions of constituent phases in cement pastes at various ages. The volume fractions of unhydrated cement remarkably decreased for the initial hydration of 24 hours, but subsequent reduction in the volume fraction of unhydrated cement in the cement paste with a water/cement ratio of 0.25 was not so conspicuous as in other cement pastes. The volume of pores detected by the backscatter image (i.e. coarse capillary pores) also decreased with time, in concert with the decrease in the volume of unhydrated 
cement. As expected, the higher the water/cement ratio, the greater the volume fraction of coarse capillary pores in the cement pastes at any given age.

Fig.3 shows the degrees of hydration of cement which were calculated with Equation (1) using volume fractions of unhydrated cement measured by the BSE image analysis (Fig.2). About a half of the cement has reacted for the first 24 hours in the cement pastes with water/cement ratios of 0.25 and 0.40 . The higher the water/cement ratio of cement pastes, the lower the degree of hydration up to the age of 3 days. However, thereafter, the degree of hydration steeply increased with increasing water/cement ratio, so that the cement paste with a water/cement ratio of 0.6 achieved the highest value of about $90 \%$ at 91 days. It should be noted that the degree of hydration in the cement paste with a water/cement ratio of 0.25 was little changed after 3 days, and approached an ultimate degree of hydration of 0.69 . This corresponds to the ultimate degree of hydration in water estimated by the Powers model.

\subsection{Changes in phase fractions with the degree of hydration}

The volume of hydration products can be calculated with a model for the hydration of cement. In this study, the Powers model was applied to the results of image analysis. In the calculation, the volume of cement gel produced by the hydration of $1 \mathrm{~cm}^{3}$ dry cement was assumed to be $2.1 \mathrm{~cm}^{3}$. The non-evaporable water content in the reacted cement is assumed to be about $23 \%$ by mass. Chemical shrinkage was also assumed to be 0.254 of the volume of non-evaporable water [9]. The porosity of cement gel used in the calculation was $28 \%$; gel pores were assumed to be saturated with gel water. The volume of cement gel was estimated using the degree of hydration determined by Equation (1). The volume of capillary pores was obtained by subtracting the volume of residual unhydrated cement and the calculated volume of cement gel from the initial volume of the mixture. Thus, differences in the volume fraction between the capillary pore volumes calculated based on the Powers model and the coarse pore volumes obtained by the image analysis represent the volume fractions of fine pores of diameters less than the resolution of the image analysis $(0.2 \mu \mathrm{m}$ in this study).

Assuming that excess water was supplied from outside, the calculated volume fractions of 
constituent phases in cement pastes with various water/cement ratios are given in Fig.4. The volume fraction of capillary pores calculated on the Powers model (the sum of coarse and fine pores in Fig.4) was always greater than that of coarse pores $(>0.2 \mu \mathrm{m})$ obtained by the image analysis. These results indicate that considerable amounts of fine capillary pores not counted in the image analysis exist. It has been pointed out that the BSE image analysis could detect large capillary pores not measured by the mercury intrusion porosimetry [8]. A noteworthy result obtained in this study is that amounts of small and medium capillary pores $(0.05 \mu \mathrm{m} \sim 0.0026 \mu \mathrm{m})$ and parts of large capillary pores $(0.2 \mu \mathrm{m} \sim 0.05 \mu \mathrm{m})$ not counted by the BSE image analysis were extremely small in the cement paste with a low water/cement ratio of 0.25 , compared with the cement pastes with water/cement ratio of 0.40 and 0.60 . In 91-day-old cement pastes with a low water/cement ratio of 0.25 , the medium-sized pores $(0.2 \mu \mathrm{m} \sim 0.0026 \mu \mathrm{m})$ have disappeared, but some amounts of larger capillary pores than $0.2 \mu \mathrm{m}$ existed.

It is also found from Fig.4 that an increase in water/cement ratio results in a decrease in the volume of solid phases(hydration products + unhydrated cement). However, differences in the degree of hydration reflecting the volume of unhydrated cement between different water/cement ratios were not so great as differences in the solid volume in cement pastes with various water/cement ratios because of lack in parts of fine pores (Fig.4). It is found from these results that the image analysis gave more quantitative evaluation for capillary pore structures if the presence of fine capillary pores was taken into account by the combination with the Powers model. Furthermore, it should be noted that volume fractions of fine capillary pores at a low water/cement ratio of 0.25 were far less than those in cement pastes with water/cement ratios of 0.40 and 0.60 . Especially, the application of the Powers model to the results obtained by the image analysis provides a conclusion that at 91 days, such fine capillary pores were not present. As for cement pastes with higher water/cement ratios of 0.4 and 0.6 , the volume fractions of fine pores were little changed with time. Lack in capillary pores ranging from $0.2 \mu \mathrm{m}$ to $2.6 \mathrm{~nm}$ and the presence of considerable amounts of pores larger than $0.2 \mu \mathrm{m}$ in 91-day-old cement pastes with a low water/cement ratio of 0.25 mean that pore size distributions in the cement pastes may be discontinuous, i.e. "gap-graded". Namely, their pore size distribution is almost absent in the range of medium sized pore although the pore distribution is generally considered to change 
gradually from macropores to micropores through mesopores. The coarse pores are found to be embedded in the C-S-H gel matrix in cement pastes with an extremely low water/cement ratio of 0.25 (Fig.1(c)). Naturally, a part of coarse pores observed may be derived from isolated Hadley grains. However, only a few Hadley grains were found in a BSE image of 500 magnifications even at the age of 91 days (Fig.1(c)).The characteristic of pore structure in cement pastes with an extremely low water/cement ratio is considered to be important in the mechanism of concrete deterioration in a freeze-thaw environment.

The solids and pores phase constitutions shown in Fig.4 also represent the characteristics of deposition of hydration products under various water/cement ratios. At high water/cement ratios, enough water and spaces are available for the formation of hydration products. As hydration of cement proceeds, refinement of pores may occur in all the ranges of capillary pore sizes. As already described, reductions in large pores were accompanied by the formation of fine capillary pores and increases in solid phase. The translation of large pores to fine pores is found in Fig.4. However, at an extremely low water/cement ratio of 0.25 , amounts of free water may not be large enough for the progress of hydration. In such a cement paste, C-S-H gel was produced, but large pores were not sufficiently filled with hydration products so that they might be left in the cement paste.

\subsection{Effects of mineral admixtures on the degree of hydration of cement}

The degrees of hydration in cement pastes with mineral admixtures are presented in Fig.5. It is found from Fig. 5 that the degree of hydration of cement in pastes with the mineral admixtures was higher than that in admixture-free pastes at early ages. As reported by some workers $[12,13]$, the acceleration of hydration of cement by the addition of fly ash and silica fume was also indicated in this study. On the assumption that the volume fraction of silica fume and fly ash are assumed not to change with time, the volume fractions of the phases in these cement pastes were calculated (Fig.6). As shown in Fig.6, differences in the fractions of hydration products between the cement pastes with and without mineral admixture were small. However, it should be noted that the cement pastes with fly ash contained more coarse capillary pores than others at the age 
of 3, 7 and 28 days. However, the total amounts of coarse and fine capillary pores were almost the same in all the cement pastes. This result agrees with a generally accepted concept that low-calcium fly ashes do not react appreciably at early ages[14]. The volume fractions of phases in mortars with mineral admixtures are presented in Fig.7. There are no differences in the proportions of phases between pastes and mortars. The addition of sand grains did not affect phase constituents in cement paste.

\subsection{Correlation of capillary pore volumes with compressive strength of cement pastes and mortars}

Fig. 8 shows the relationship between compressive strength $\left(\sigma_{\mathrm{c}}\right)$ and coarse capillary pore porosity (x) for cement pastes and mortars. The relationship between the two can be written as Equation (2).

$\sigma_{c}=C_{0} e^{n x}$

where, $\mathrm{C}_{0}$ is a constant representing the strength of the matrix containing no capillary pores larger than $0.2 \mu \mathrm{m}$. The value of $n$ was -16.7 in this case. Correlation between the two was good. However, if the compressive strength versus capillary porosity for each water/cement ratio is considered separately, the relationship of porosity to strength can be represented by the linear regression shown in Fig.8(b). The dependence of compressive strength on the coarse capillary porosity is found to be slightly different for the different water/cement ratios. As shown by broken lines of regression in Fig.8(b), the gradient of each regression line decreased with increasing water/cement ratio. These results suggest that the relationships between the strength and the porosity of coarse pores detected by the image analysis are linear, but that the slope of a straight line relation increases with decreasing water/cement ratio of cement pastes and mortars. It is also found from Fig.8(b) that data for both cement pastes and mortars of a given water/cement ratio are plotted along the same straight regression line.

The gel/space ratio in the Powers-Brownyard expression [15] for estimating compressive strength of mortars can be calculated using the degree of hydration obtained by Equation (1). The relationship between compressive strength and the gel/space ratio determined by the BSE image analysis is presented in Fig.9. It is found that the relationship between compressive strength and the gel/space ratio can be written by the same 
form of expression as Powers and Brownyard proposed [15]. However, the compressive strength of mortars at a given gel/space ratio in this study was considerably smaller than that estimated by the Powers-Brownyard equation. A part of the reason for the lower compressive strength found in mortars in this study may be due to the difference in the shape and size of specimen between the two studies. Furthermore, the degree of hydration determined by the image analysis on the volume basis may give slightly different values than those based on the mass proportions[11]. As suggested in Figs. 2 and 4, if the image analysis overestimates the gel/space ratio, the compressive strength at the gel/space ratio of 1.0 in the regression line may be reduced.

\section{DISCUSSION}

As mentioned above, the result of the image analysis for cement pastes and mortars appears to be consistent with the Powers model on the hydration of cement. Furthermore, the combination of the image analysis with the hydration model was useful for understanding significant differences in capillary pore structures in cement pastes and mortars between various water/cement ratios. Particularly, it should be noted that the cement paste with a low water/cement ratio of 0.25 had a discontinuous pore size distribution in which most of the coarse capillary pores were isolated in the backscatter images. At long ages, fine capillary pores, which are defined in this study, disappeared so that relatively large pores appeared as if isolated at long ages (Fig.4). However, in cement pastes with a relatively high water/cement ratio, considerable amounts of fine capillary pores existed even at long ages.

The presence of large capillary pores in cement pastes with an extremely low water/cement ratio may be related to the moisture conditions in the cement pastes at early ages. The hydration of cement under such an insufficient water content as in cement pastes with an extremely low water/cement ratio leads to the reduction in relative humidity within cement paste specimens even at early ages. Water menisci were generated in coarse capillary pores so that large empty pores must have been formed in the pastes. Hydration products by subsequent hydration of cement can grow in finer pores containing liquid water, but not in larger empty pores. The characteristic of volume fractions of phases in the cement paste with a water/cement ratio of 0.25 (Fig.4) 
may suggest the occurrence of self-desiccation in the process of hydration of cement at early ages.

Effects of water/cement ratio and curing time on the pore size distributions in cement pastes have been extensively investigated in terms of the MIP method $[1,16,17,18]$. It has been reported that the total porosity and the threshold diameter of pores decreased in terms of cumulative curves of pore volume. As pore size distributions move toward smaller sizes, greater strengths are achieved. The same trend in changes of pore structure with time was observed in the results of the BSE image analysis. However, it should be noted that large capillary pores, visible in the SEM were still left even in the mature cement pastes with an extremely low water/cement ratio.

As shown in Fig.4, the volume fraction of pores greater than the size of pixel $(0.2 \mu \mathrm{m})$ in the cement paste with a water/cement ratio of 0.25 was not different from that of the cement paste with a water/cement ratio of 0.40 at 91 days. However, there were great differences in strength between the cement paste with a water/cement ratio of 0.25 and 0.40 at 91 days (Fig.8). These results show that the densification in the range of fine capillary pores greatly contributed to the increase in strength. The MIP method cannot correctly evaluate variations in the amounts and sizes of large capillary pores. The densifications in microstructure of cement pastes in the MIP method have been misunderstood as a simple decrease of threshold diameter with time. Since the large capillary porosity do not play a significant role in differentiating pore structures in the mature cement pastes, the MIP has qualitatively succeeded in giving a reasonable interpretation for pore refinement in the cement systems.

By using the gel/space ratio calculated from the result of image analysis, the compressive strength of cement pastes and mortars could be expressed as the same function of gel/space ratio as Powers and Brownyard proposed [15]. As mentioned above, Figs.4 and 9 also appear to indicate that parts of the increase in strength resulted from the densification of microstructure in the range of fine capillary pores, in particular at long ages. This is to say, the reduction of porosity in the medium-sized pores was accompanied by the increase in the gel/space ratio. The presence of coarse capillary pores at a water/cement ratio of 0.25 was not so crucial in the development of strength as far as those coarse pores are properly dispersed so as to be isolated. This fact suggests that spatial distribution and connectivity of large pores are important in the development of strength 
in concretes, but that the elimination of the coarse capillary pores leads to an increase in the strength of the ultra-high strength concrete.

\section{CONCLUSIONS}

The effects of water/cement ratio and mineral admixtures on the microstructure of cement pastes and mortars were evaluated by the combination of the BSE image analysis with the Powers model. The major results obtained are as follows;

(1) Considerable amounts of large capillary pores which are not correctly measured in the MIP method exist in cement pastes. These large pores decreased with time, and were fewer for lower water/cement ratios.

(2)The degrees of hydration determined by the BSE image analysis were consistent with the Powers model for hydration of cement. The presence of fine capillary pores $(0.2 \mu \mathrm{m}-2.6 \mathrm{~nm})$ predicted on the basis of the Powers model characterized the capillary pore structures. The development of strength in cement pastes appears to result from the elimination of these fine pores, produced by the increase in hydration products.

(3)At an extremely low water/cement ratio of 0.25 , there were little fine capillary pores at long ages. The coarse capillary pores in the cement paste with a low water/cement ratio of 0.25 were supposed to be connected by gel pores. At a high water/cement ratio, coarse pores were subdivided into finer capillary pores. The coarse pores left in the cement paste may be still interconnected by fine capillary pores at long ages.

(4)The presence of large capillary pores may not impede the development of compressive strength in cement pastes with a low water/cement ratio at long ages.

(5) Good correlation between the compressive strength and the volume fractions of coarse capillary porosity was found. However, the sensitivity of the strength to the volume fractions of coarse capillary porosity depends on water/cement ratio.

(6) The relationship between compressive strength and the gel/space ratio calculated based on the results obtained by the BSE image analysis in mortars could be expressed by the same form as proposed by Powers 
and Brownyard.

\section{References}

[1] Diamond, S.: Mercury porosimetry: An inappropriate method for the measurement of pore size distributions in cement-based materials, Cement and Concrete Research, Vol.30, No.10, pp.1517-25, 2000.

[2] Scrivener, K.L.: Microscopy methods in cement paste and concrete, Papers to be presented, but not included in the Proceedings of the 10th International Congress on the Chemistry of Cement, Gorthenburg, Sweden, 1997

[3] Kjellsen, K.O., Detwiler, R.J. and Gjorv, O.E.: Backscattered electron imaging of cement pastes hydrated at different temperatures, Cement and Concrete Research, Vol.20, pp.308-311, 1990.

[4] Russ, J.C. and Dehoff, R.T.: Practical Stereology, Second Edition, Kluwer Academic Press, New York, USA, 2000.

[5] Scrivener, K.L. and Pratt, P.L.: Back-scattered electron images of polished cement sections in scanning electron microscope, Proc. 6th International Conference on Cement Microscopy, New Mexico, pp.145-55, 1984.

[6] Scrivener, K.L., Patel, H.H., Pratt, P.L. and Parrott, L.J.: Analysis of phases in cement paste using backscattered electron images, methanol adsorption and thermogravimetric analysis, MRS Symposium Proceedings, Vol.85, pp.67-76, 1987.

[7] Lange, D.A., Jennings, H.M. and Shah, S.P.: Image analysis techniques for characterization of pore structure of cement-based materials, Cement and Concrete Research, Vol.24, No.5, pp.841-853, 1994.

[8] Diamond, S. and Leeman, M.E.: Pore size distributions in hardened cement paste by SEM image analysis, MRS Symposium Proceedings, Vol.370, pp.217-226, 1995.

[9] Powers, T.C.: Physical properties of cement paste, Proceedings of the $4^{\text {th }}$ International Symposium on the Chemistry of Cement, Vol.1, pp.577-613, 1960.

[10] Kjellsen, N.O., Detwiler, R.J. and Gjorv, O.E.: Backscattered electron image analysis of cement paste 
specimens: specimen preparation and analytical methods, Cement and Concrete Research, Vol.21, pp.388-390, 1991.

[11] Kjellsen, N.O. and Fjallberg, L.: Measurements of the degree of hydration of cement paste by SEM, ${ }^{29}$ NMR and XRD methods, Proc. Workshop on Water in Cement and Concrete Hydration and Pore Structure, Skagen Denmark, The Nordic Concrete Federation, pp.85-98, 1999.

[12] Taylor, H.F.W.: Cement Chemistry, Thomas Telford, London, 1997.

[13] Wu, Z.-Q. and Young, J.F.: The hydration of tricalcium silicate in the presence of colloidal silica, Journal of Materials Science, Vol.19, No.11 , pp.3477-3486, 1984.

[14] Diamond, S: The characterization of fly ashes, Proc. Symp. Annual Meeting of MRS, pp.12-13, 1981.

[15] Powers, T.C. and Brownyard, T.L.: Studies of the physical properties of hardened cement pastes (Nine parts), Journal of American Concrete Institute, No.43, 1946-47.

[16] Winslow, D.N. and Diamond, S.: A mercury porosimetry study of the evolution of porosity in Portland cement, Journal of Materials, Vol.5, No.3, pp.564-585, 1970.

[17] Cook, R.A. and Hover, K.C.: Mercury porosimetry of hardened cement pastes, Cement and Concrete Research, Vol.29, No.6, pp.933-943, 1999.

[18] Uchikawa, H.: Effect of blending components on the hydration and structure formation of blended cement, Part4, Journal of Cement and Concrete, No.488, pp.33-48, 1987 (in Japanese). 


\section{Figure Captions}

Figure1 BSE image micrographs of cement pastes: (a) Admixture-free at 1day (Water/cement ratio=0.40)

(b)Fly ash-containing at 1 day (Water/binder ratio=0.40) (c) Admixture-free at 91 days (Water/cement ratio $=0.25)$

Figure 2 Measured volume fractions of constituent phases in cement pastes

Figure 3 Degrees of hydration in cement pastes without admixture

Figure 4 Calculated volume fractions of constituent phases in cement pastes (Coarse pores : $>0.2 \mu \mathrm{m}$ Fine pores: $0.2 \mu \mathrm{m}-2.6 \mathrm{~nm})$

Figure 5 Degrees of hydration in cement pastes with a mineral admixture

Figure 6 Volume fractions of constituent phases in w/c ratio 0.4 cement pastes with a mineral admixture (Coarse pores: $>0.2 \mu \mathrm{m}$ Fine pores: $0.2 \mu \mathrm{m}-2.6 \mathrm{~nm}$ )

Figure 7 Volume fractions of constituent phases in w/c ratio 0.4 cement mortars with a mineral admixture (Coarse pores: $>0.2 \mu \mathrm{m}$ Fine pores: $0.2 \mu \mathrm{m}-2.6 \mathrm{~nm}$ )

Figure 8 Correlation between compressive strength and coarse capillary porosity (a) Non linear regression for all data (b) Linear regression for various water/cement ratios

Figure 9 Compressive strength vs. gel/space ratio for mortars without admixtures 
Table 1 Physical properties of admixtures

\begin{tabular}{l|c|c} 
& Silica Fume & Fly Ash \\
\hline Density $\left(\mathrm{g} / \mathrm{cm}^{3}\right)$ & 2.20 & 2.19 \\
Specific Surface & 20.0 & 0.345 \\
Area (m²/g) & 1.20 & 0.70 \\
Ignition Loss (\%) & 90.8 & 70.9 \\
$\mathrm{SiO}_{2}(\%)$ & \\
\hline
\end{tabular}

Table 2 Mix proportions of cement pastes and mortars

\begin{tabular}{|c|l|c|c|c|}
\hline \multicolumn{2}{|c|}{} & $\begin{array}{c}\text { Water/Binder } \\
\text { Ratio }\end{array}$ & $\begin{array}{c}\text { Replacement } \\
\text { Ratio (\%) }\end{array}$ & Binder : Sand \\
\hline \multirow{3}{*}{$\begin{array}{c}\text { Cement } \\
\text { Paste }\end{array}$} & Admixture-free & 0.25 & 0 & $1: 0$ \\
& & 0.4 & 0 & $1: 0$ \\
& Silica Fume paste & 0.6 & 0 & $1: 0$ \\
\hline \multirow{4}{*}{ Mortar } & Fly ash paste & 0.4 & 10 & $1: 0$ \\
& & 0.25 & 15 & $1: 0$ \\
\cline { 2 - 5 } & Admixture-free & 0.4 & 0 & $1: 2$ \\
& & 0.6 & 0 & $1: 2$ \\
& Silica Fume mortar & 0.4 & 10 & $1: 2$ \\
\hline & Fly ash mortar & 0.4 & 15 & $1: 2$ \\
\hline
\end{tabular}




\section{(b)}

(b) 0.20

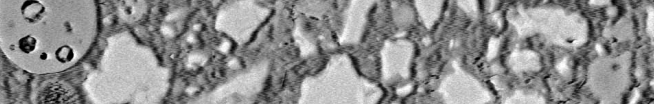

3.

$x_{0}$

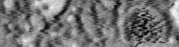

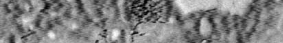

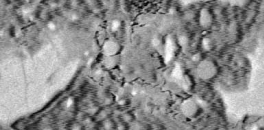

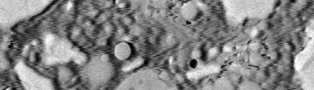

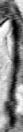

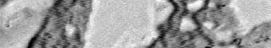
S as. (3): (1)

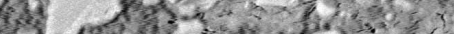

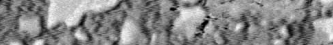

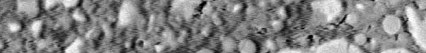

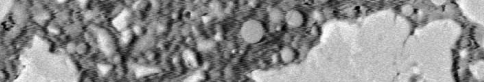

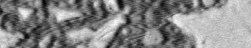

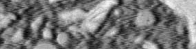

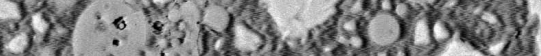

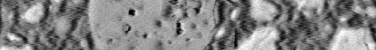

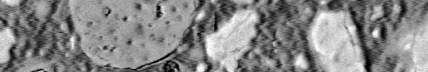
I. s. 3.5
3 (a)

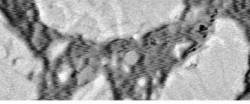

$100 \mu \mathrm{m}$ 


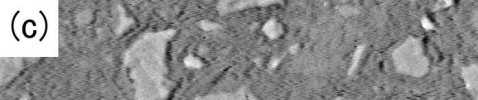

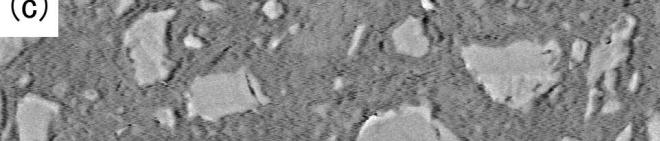

W. $(x, 3,3$ in

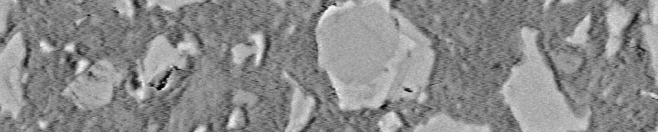

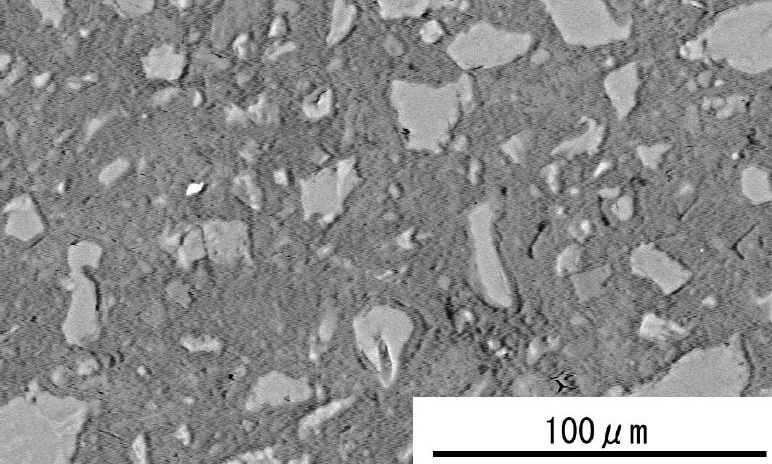



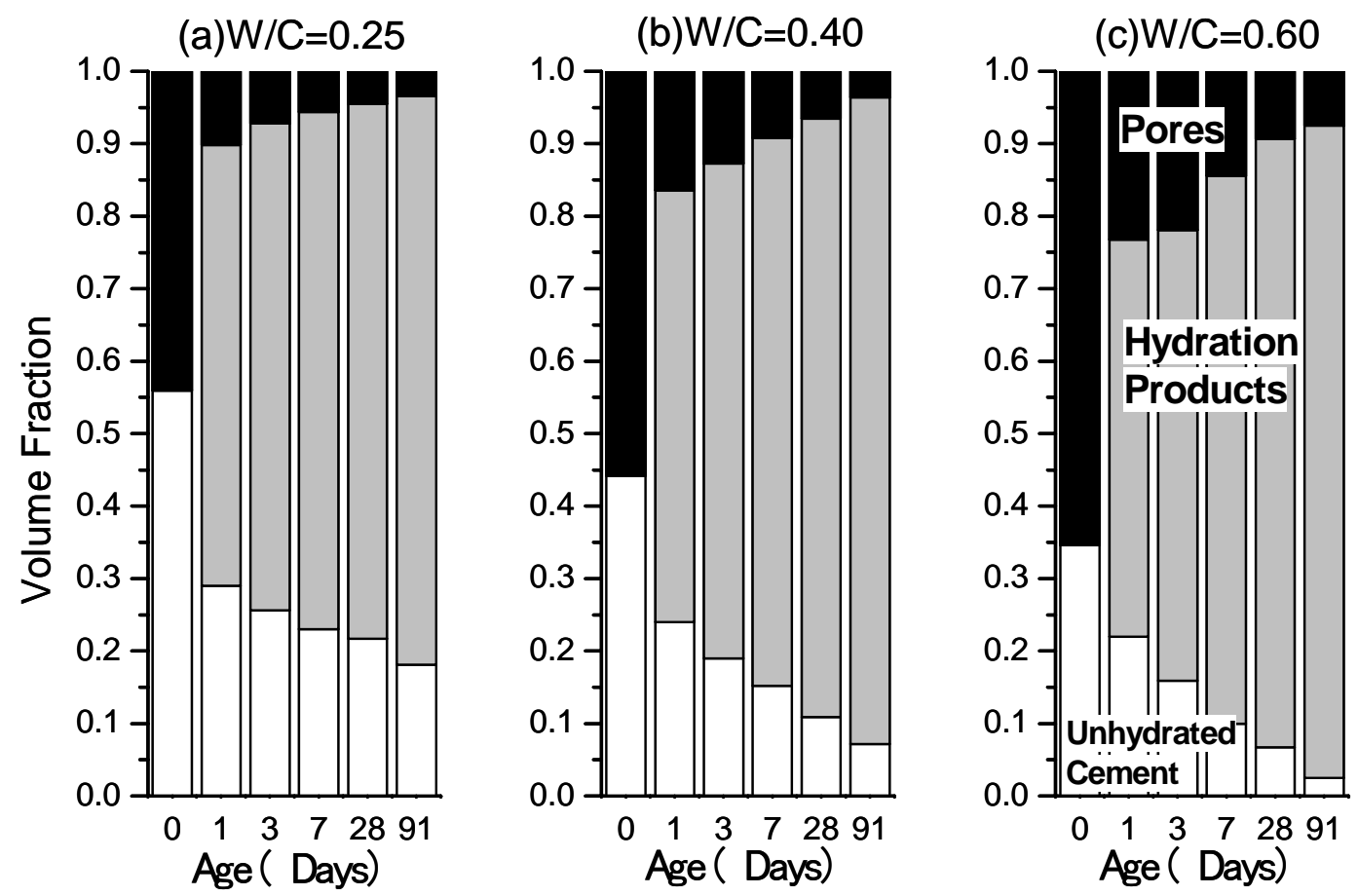

Figure 2 Measured volume fractions of constituent phases in cement pastes 


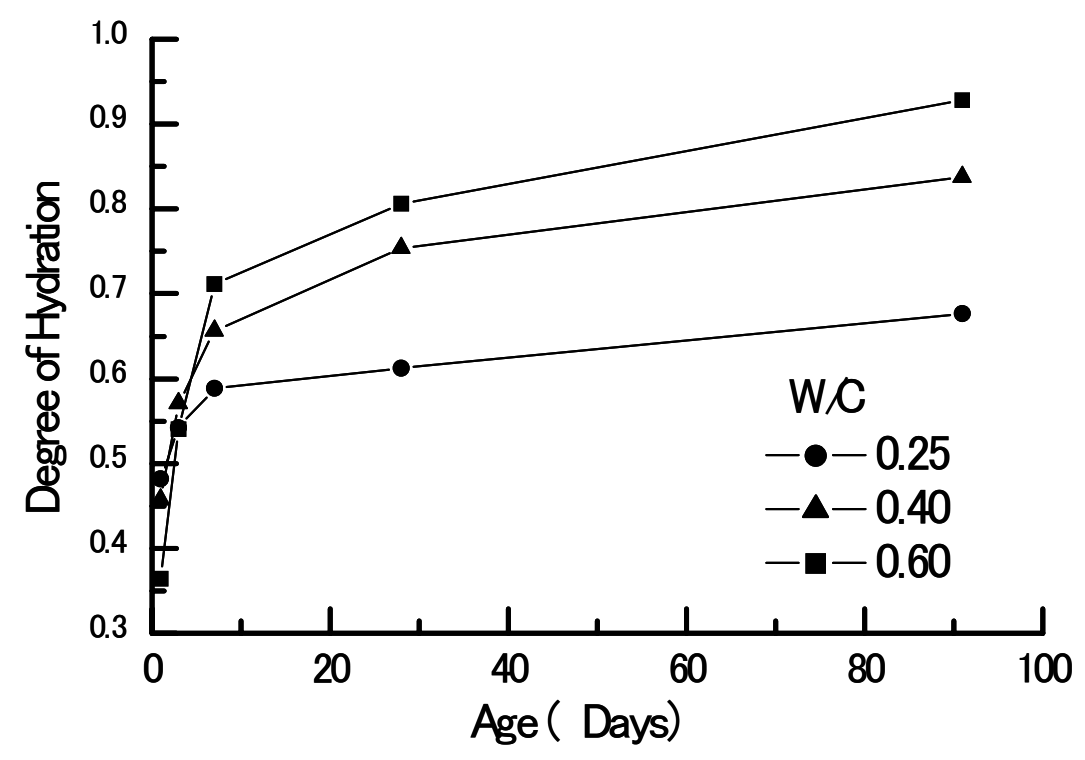

Figure 3 Degrees of hydration in cement pastes without admixture 
(a) $\mathrm{W} / \mathrm{C}=0.25$

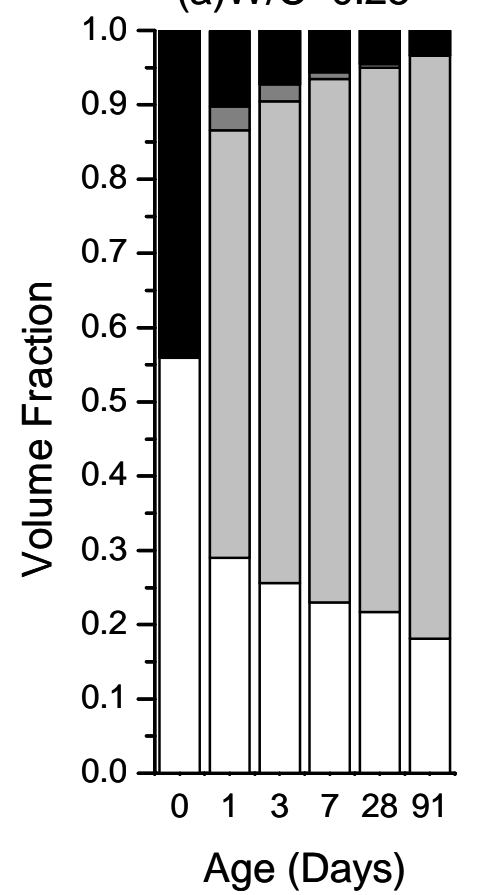

(b) $\mathrm{W} / \mathrm{C}=0.40$

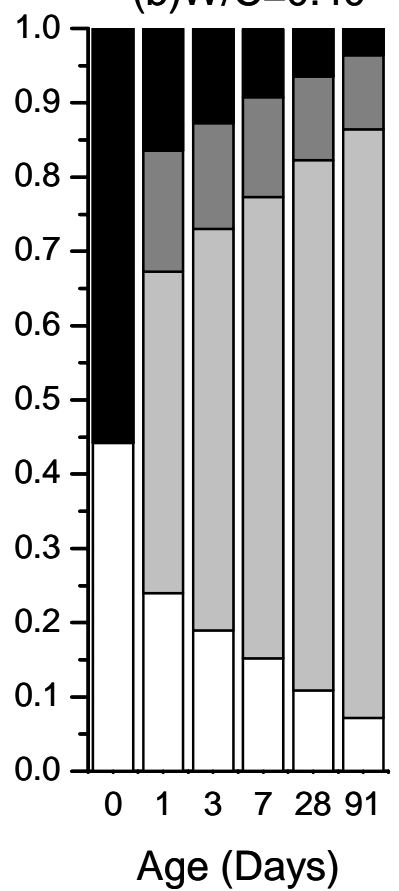

(c) $\mathrm{W} / \mathrm{C}=0.60$

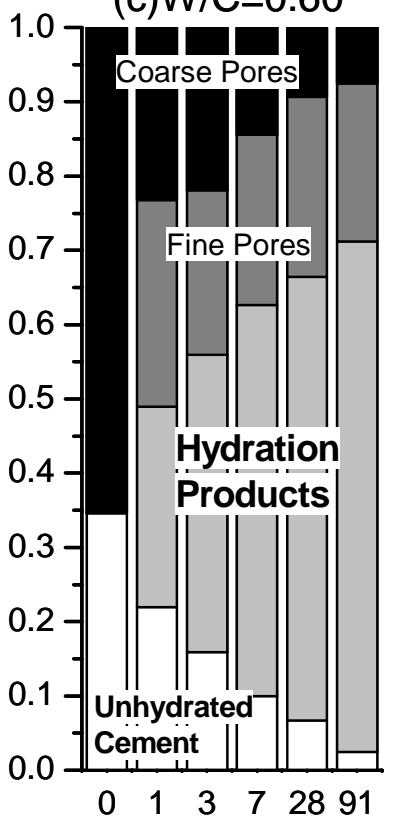

Age (Days)

Figure 4 Calculated Volume fractions of constituent phases in cement pastes Coarse pores: $>0.2 \mu \mathrm{m}$ Fine pores:0.2 $\mu \mathrm{m}-2.6 \mathrm{~nm}$ 


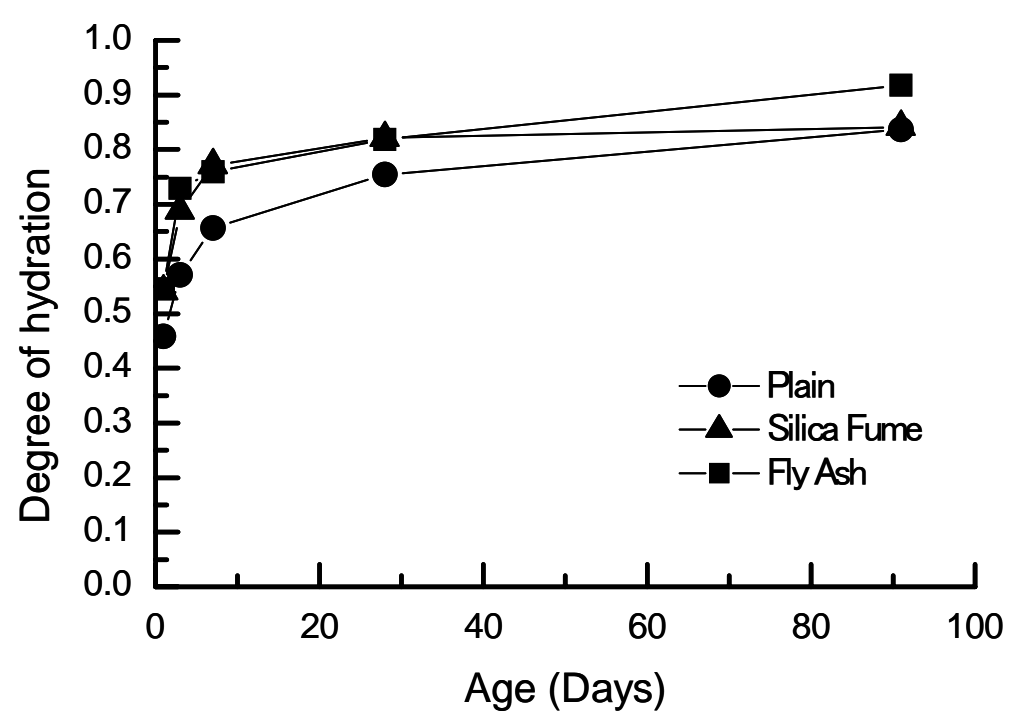

Figure 5 Degrees of hydration in cement pastes with a mineral admixture 

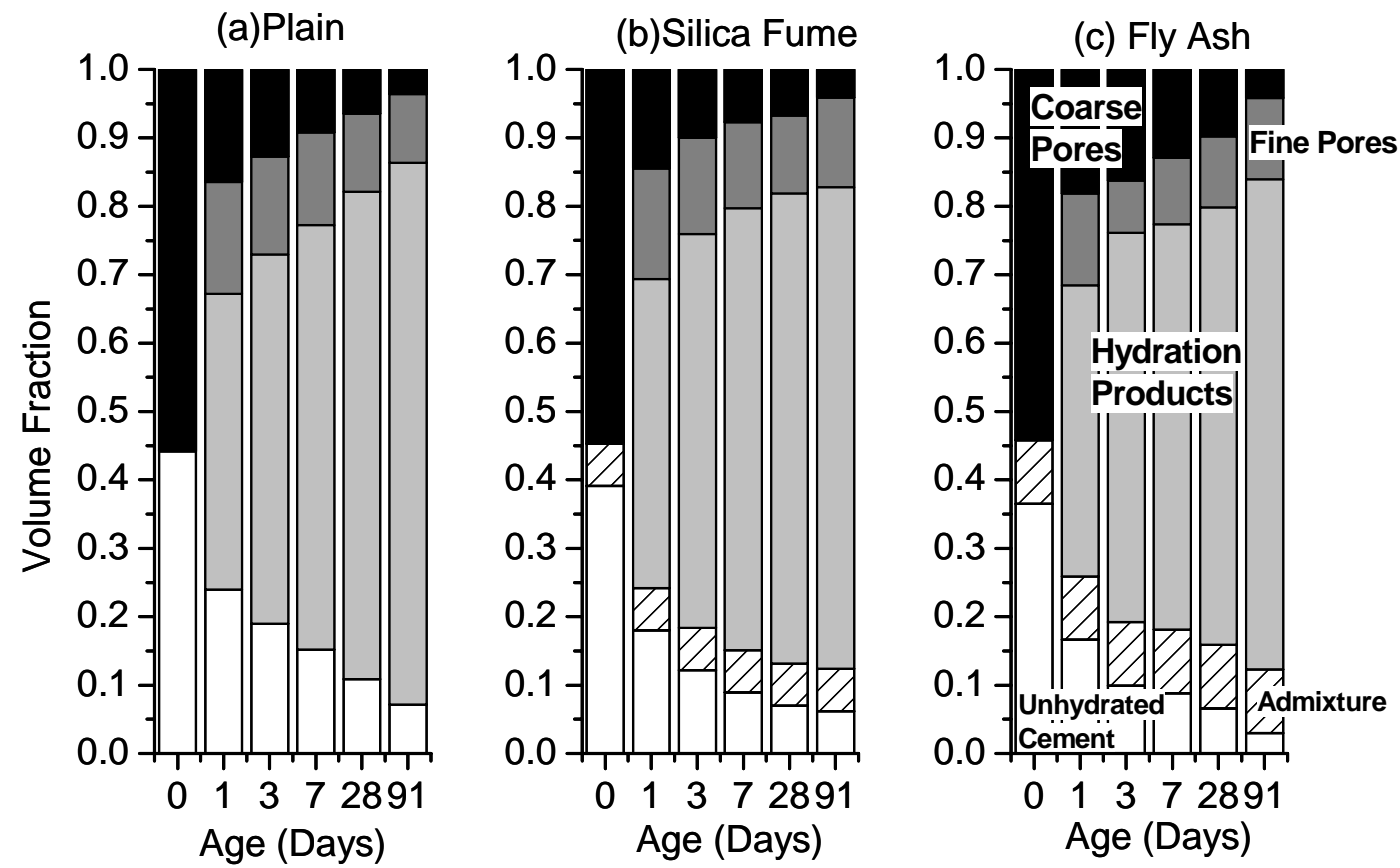

Figure 6 Volume fractions of constituent phases in w/c ratio 0.4 cement pastes with a mineral admixture Coarse pores: $>0.2 \mu \mathrm{m}$ Fine pores: $0.2 \mu \mathrm{m}-2.6 \mathrm{~nm}$ 
(a) Plain

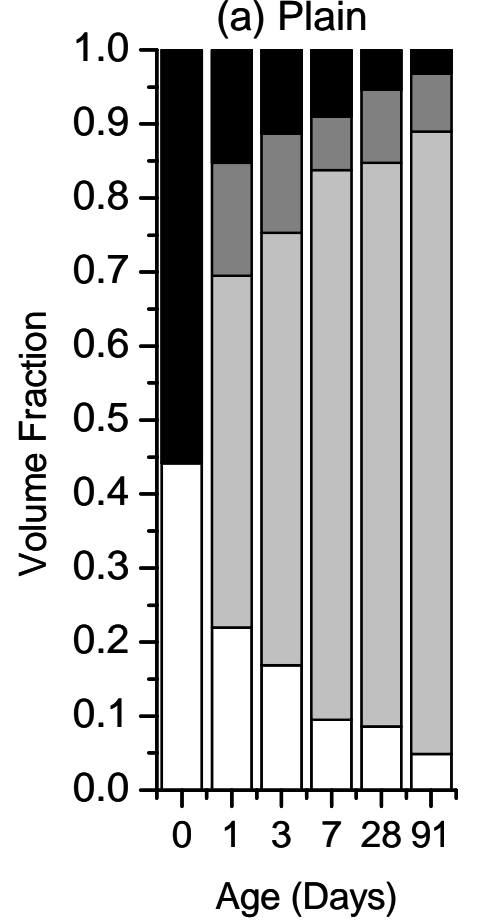

(b) Silica Fume

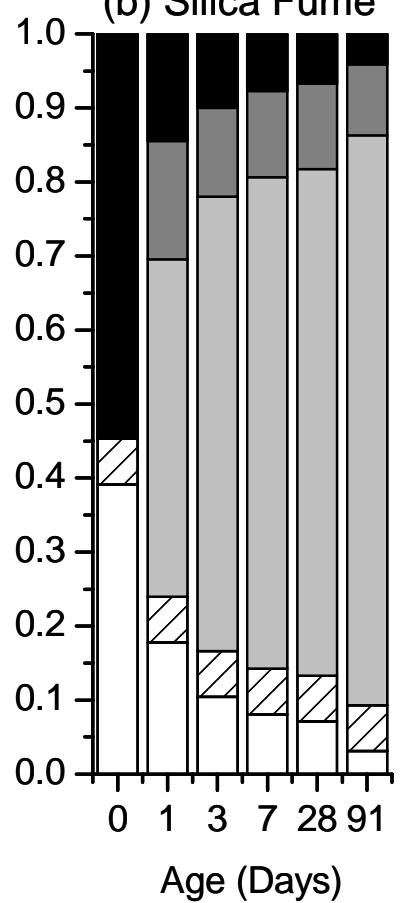

(c) Fly Ash

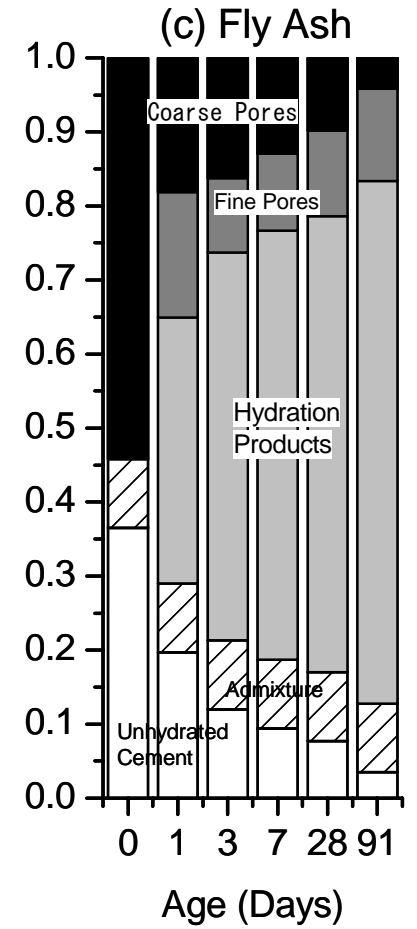

Figure 7 Volume fractions of constituent phases in w/c 0.40 mortars with a mineral admixture Coarse pores: $>0.2 \mu \mathrm{m}$ Fine pores:0.2 $\mu \mathrm{m}-2.6 \mathrm{~nm}$ 


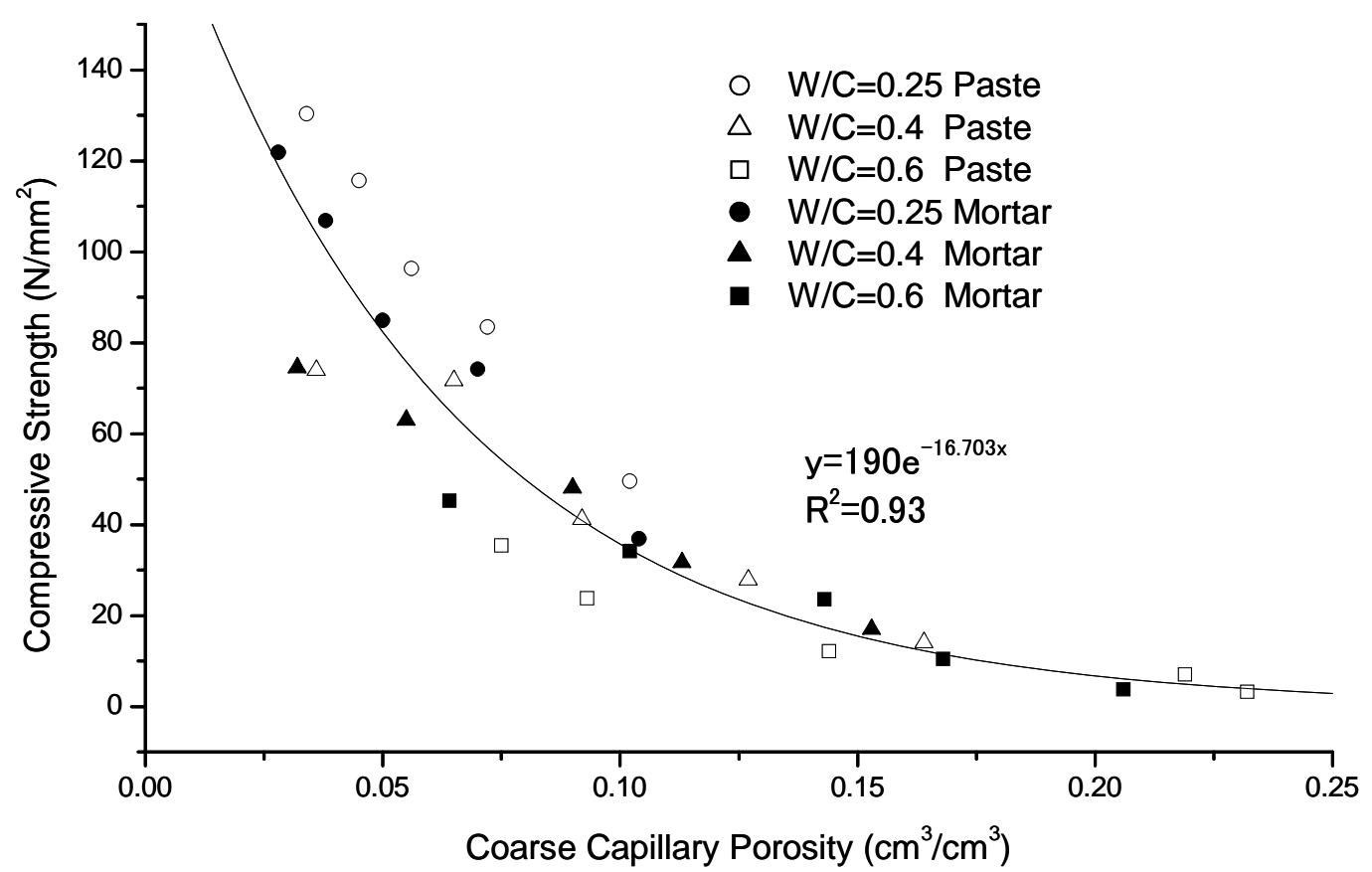

Figure 8 Correlation between compressive strength and coarse capillary porosity

(a) Non linear regression for all data 


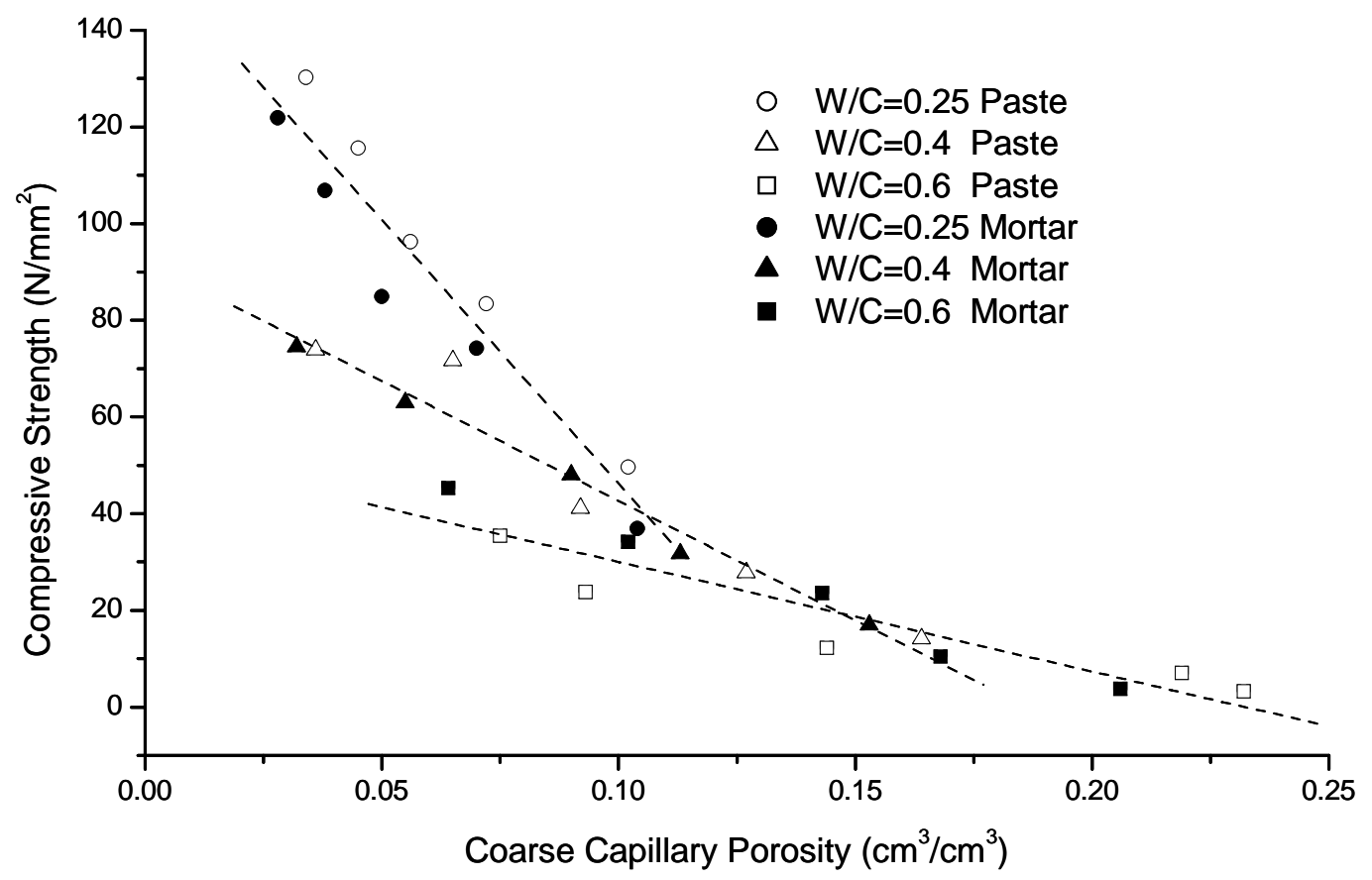

Figure 8

(b)Linear regressions for various water/cement ratios 


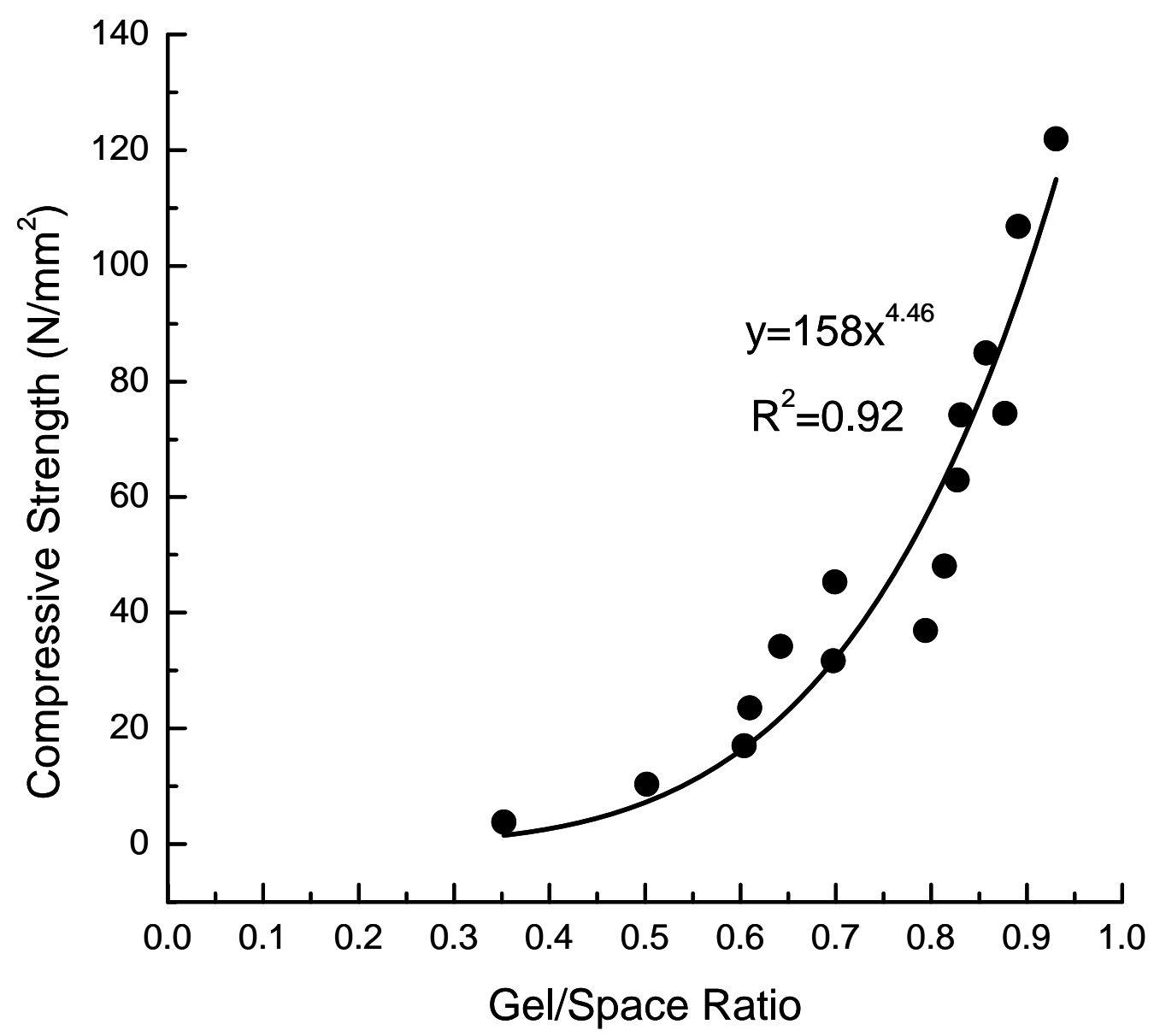

Fig.9 Compressive strength vs. gel/space ratio for mortars without admixtures 